\title{
Artificial intelligence assisted technology for ground support construction
}

\author{
B Chen GroundProbe Pty Ltd, Australia \\ T Harrington BHP, Australia \\ P Ayres Orica Hong Kong Ltd, Hong Kong \\ L-P Gélinas Agnico Eagle Mines Limited, Canada
}

\begin{abstract}
The typical underground mining development and reconciliation process across the world utilises the common design, construct, verify and rework methodology. The primary focus of a mining development contractor is to meet the required development schedule. Hence, the development cycle is often designed and optimised to reduce the cycle time and increase the advance rate. The reconciliation of development headings is time consuming, and often a manually intensive process of verifying the installation against design via survey. Hence, this is often left as a secondary task with long delays between any feedback to the development crews.

Leveraging the latest in artificial intelligence technology, high density LiDAR and high speed computing systems can provide the ability for development crews to receive real-time in-cycle feedback on their ground support construction and also to monitor the effectiveness of the ground support. This has potential to significantly increase the efficiency and quality of reinforcement, whilst reducing wastage in development.
\end{abstract}

Keywords: Al technology, LiDAR, shotcrete thickness, convergence, effectiveness of ground support

\section{Current development and ground support construction challenges}

Ground support construction in a development cycle, or rehabilitation of existing infrastructure, both share similar challenges. These challenges are the result of ground support installation without adequate guidance or without the ability to verify the effectiveness of the support in a dynamically changing environment. In a typical shotcrete application stage, the thickness of shotcrete applied is highly dependent on the skill and experience of the nozzle operator. The compliance of the sprayed thickness against design requirements is not known until spraying is completed and after survey pickup, highlighting areas of overspray or underspray. Consequently, this results in shotcrete wastage or costly rework.

Conventionally, to verify the effectiveness of the current ground support installation, survey pickups play a key role, with measurements of convergence utilised to help verify the effectiveness of the ground support. To achieve the required accuracy for feedback into the ground support strategy is very labour intensive and time consuming, often taking hours of manual processing before reports can be provided to the construction crew. This is often too late, and rework may need to occur. Also, due to the required time and resources to undertake this, it is not common practice.

Similarly, during the drill-and-blast cycle, valuable information such as the pull length, overbreak and underbreak volume and the as-drilled deviation data of each heading, is often not available to the drill-and-blast crew until many rounds after. This delay of information hinders the ability to control and optimise the blast perimeter.

This paper attempts to demonstrate how modern technology can address these challenges and potentially step change the current mining development practice to increase efficiencies in construction. 


\section{State-of-the-art technology in construction}

\subsection{LiDAR technology}

LiDAR scanners have been used in mapping of underground mines for many years. However, the recent development of high resolution and high speed LiDAR scanners has seen a step change in its capability when compared to scanners that were available five years prior. This advancement in acquisition speed and pixel density allows like-for-like recording of the construction, delivering a digital twin of the current construction. This speed also allows LiDAR scanners to be used in-cycle without adversely impacting the cycle time of construction.

The process of LiDAR scanning for reconciliation is commonly carried out by the survey team, where the laser scanner is deployed in the excavation heading to collect the as-built scan data. This scan data is then brought up to the surface where a process of registration is done on a high compute-power desktop computer to produce the data in a georeferenced coordinate system. Subsequently, the point cloud dataset is put through some manual processing to correct for measurement errors. Finally, it is cross-correlated to the design data before producing a report that can be used for analysis and feedback to the construction crew. This process typically takes between two to four hours per heading. Hence, the use of such technology in mining development is limited.

\subsection{Artificial intelligence technology}

Artificial intelligence (Al) technology has been in development for at least the last 20 years. The overarching Al technology incorporates many key frameworks in computer vision, image processing, digital signal processing, natural language, machine learning and deep learning and many more. However, since the demonstration by Deepmind Technology in 2014 (currently owned by Google), where they demonstrated the self-learning software program that was able to learn and master a suite of Atari games without any manual intervention. This sparked the subsequent acquisition of Deepmind and development of the first deep learning framework (TensorFlow) by Google.

Since then, much focus on Al development has been shifted to the development of convolutional neural network (CNN) engines by major players like Uber, Nvidia, Google, and Facebook. These developments were focused on producing multiple pretrained models that allow the computer to learn by feeding the program with a large amount of labelled information such as pictures of cats. The sole purpose of the CNN framework is to allow the computer to visualise many images of the same object and allows it to predict and classify these objects, ultimately identifying the object in the image.

Figure 1 shows a scan of a bolt and mesh installation. An analogy of a deep learning example is that a child may classify a bolt as a shiny thing. After years of looking at images of bolts, they will identify the bolt as metal objects with sharp edges. After this child has grown into an adult while working in an underground mine, they will see that the image actually shows Split Sets and rockbolts. In this example, many Al frameworks were being used to achieve this result. However, training models is not an easy task, due to the millions of labelled images required to train a model and the computational requirements. This makes it very difficult for such technology to be implemented in a niche industry like ground support for underground mining. 


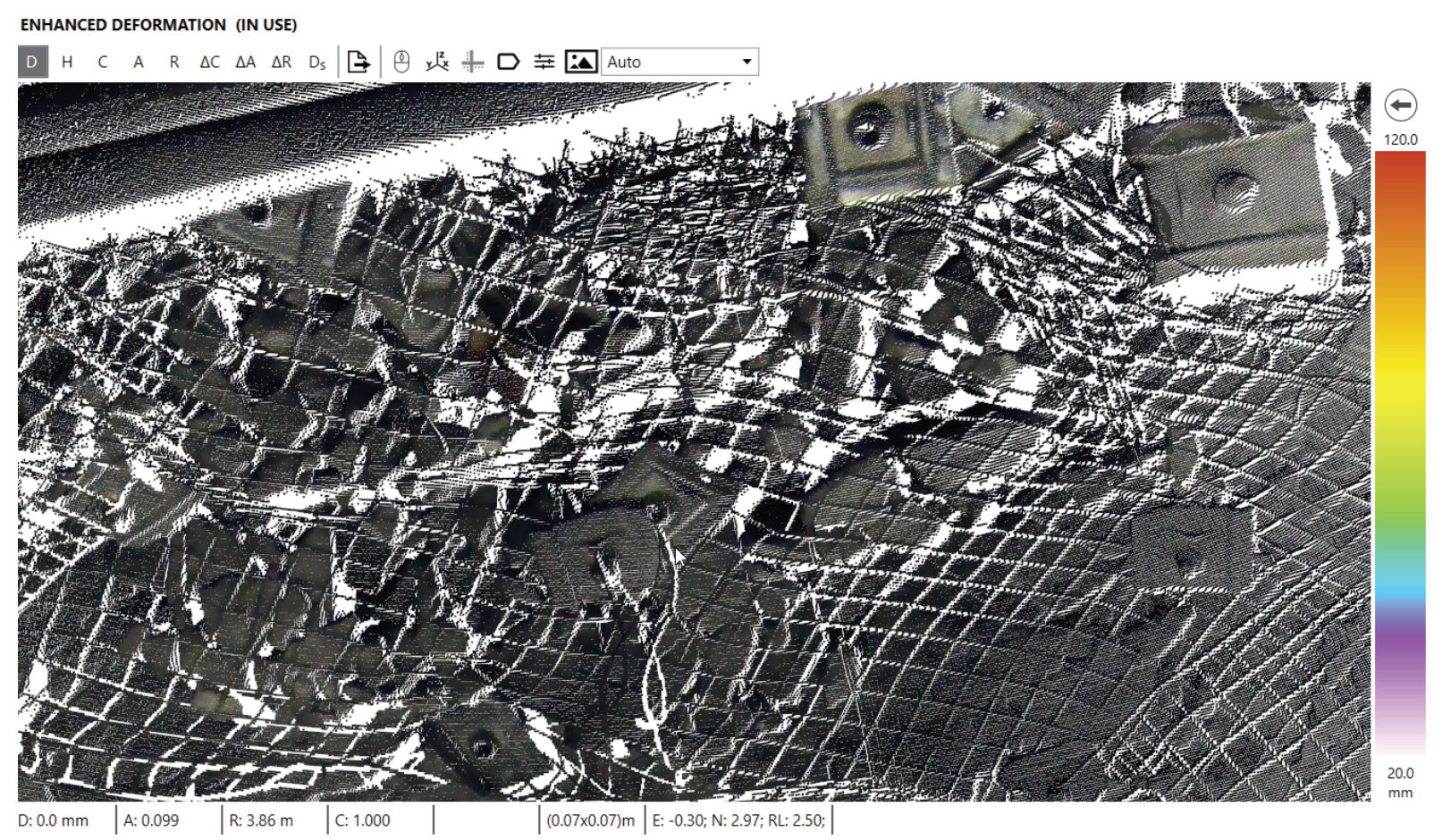

Figure 1 Typical image of bolt and mesh used for training a CNN model

\subsection{Super computing embedded computers}

The rapid adoption of high speed embedded computing platforms like field-programmable gate array (FPGA) and graphics processing unit (GPU) processor cores for embedded systems data processing has been prevalent since 2016. These technologies allow battery powered devices to achieve computing performance of one trillion floating-point operations per second (one teraflop). Part of this rapid adaption is due to the global development of algorithms and processor cores for machine learning platforms and real-time autonomous vehicle projects.

By using FPGA based system-on-chip (SoC) technology similar to the Zynq-mp processor core technology that can deliver teraflops of computing performance, the computationally intensive signal processing algorithms can be implemented in the hardware using the programmable logic area (Figure 2) (Bergmann 2005). The programmable logic area (in yellow) allows the computer designer to create custom digital signal processing cores (like GPUs) and execute them in parallel, allowing high speed processing of large datasets. This area also has the benefit of having dedicated memory banks that support concurrent access (unlike conventional computer memory access) via a common bus architecture. Hence, this allows us to process high density data similar to the 3D point cloud data produced by laser scanners in real-time. 


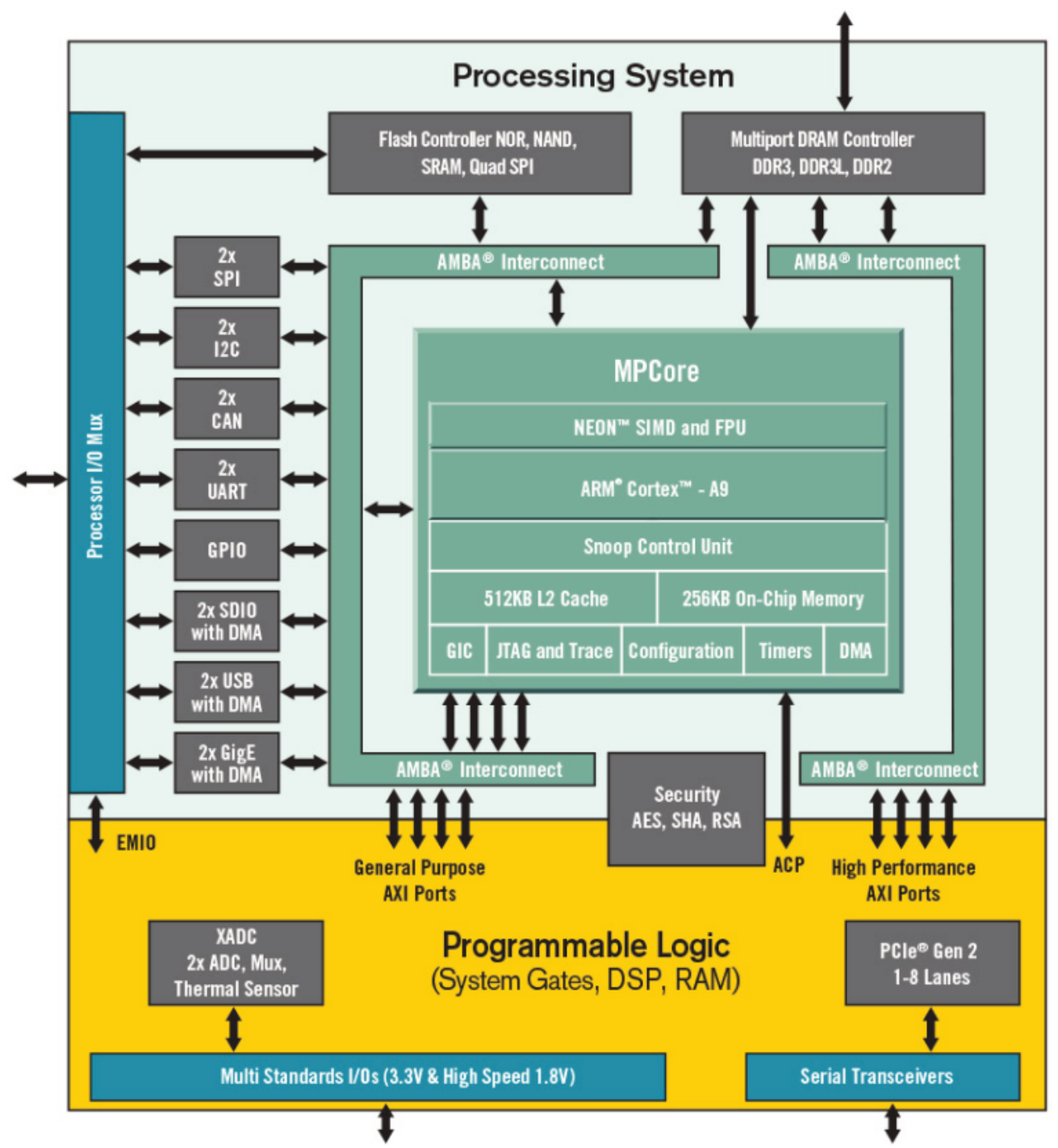

Figure 2 Xilinx FPGA architecture (Xilinx 2019)

\section{$3 \quad$ Al assisted LiDAR technology}

In this paper, Al assisted LiDAR technology refers to a portable LiDAR device that is equipped with on-board high speed computing capabilities to deliver live, or near real-time, high resolution information. One such example is the production of information such as deformation or shotcrete thickness results. An example of the technology that will be discussed in this paper is the geotechnical monitoring LiDAR (GML) as depicted in Figure 3. 


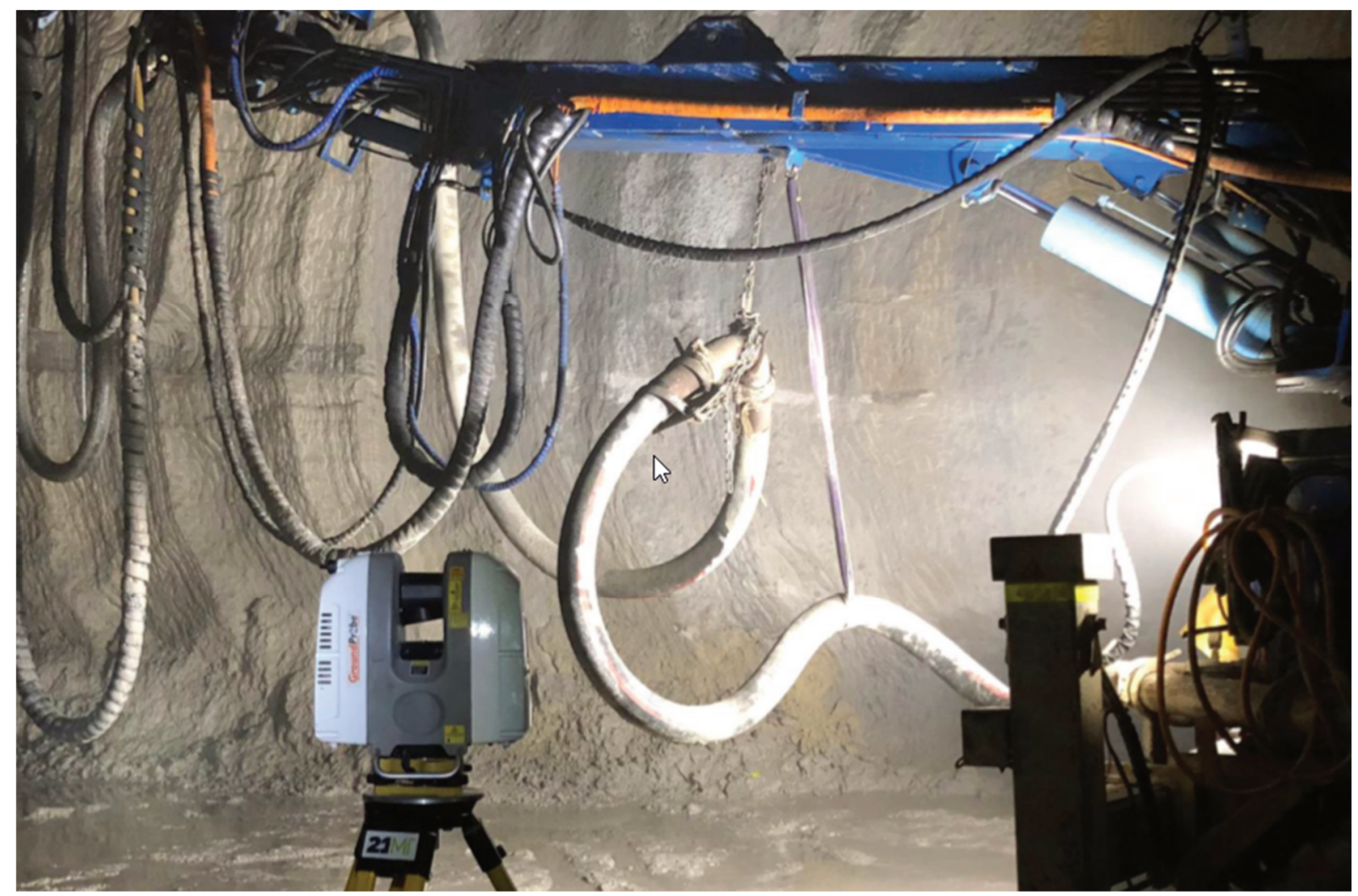

Figure 3 Geotechnical monitoring LiDAR (GML)

The GML technology by GroundProbe combines high speed computing and high resolution LiDAR, with Al technology as depicted in Figure 4, to produce a near real-time, in situ construction verification tool. Construction design profiles can also be loaded into the system prior to scanning. The system is deployed with a scanner, tablet, and tripod, allowing a single person to operate the technology.

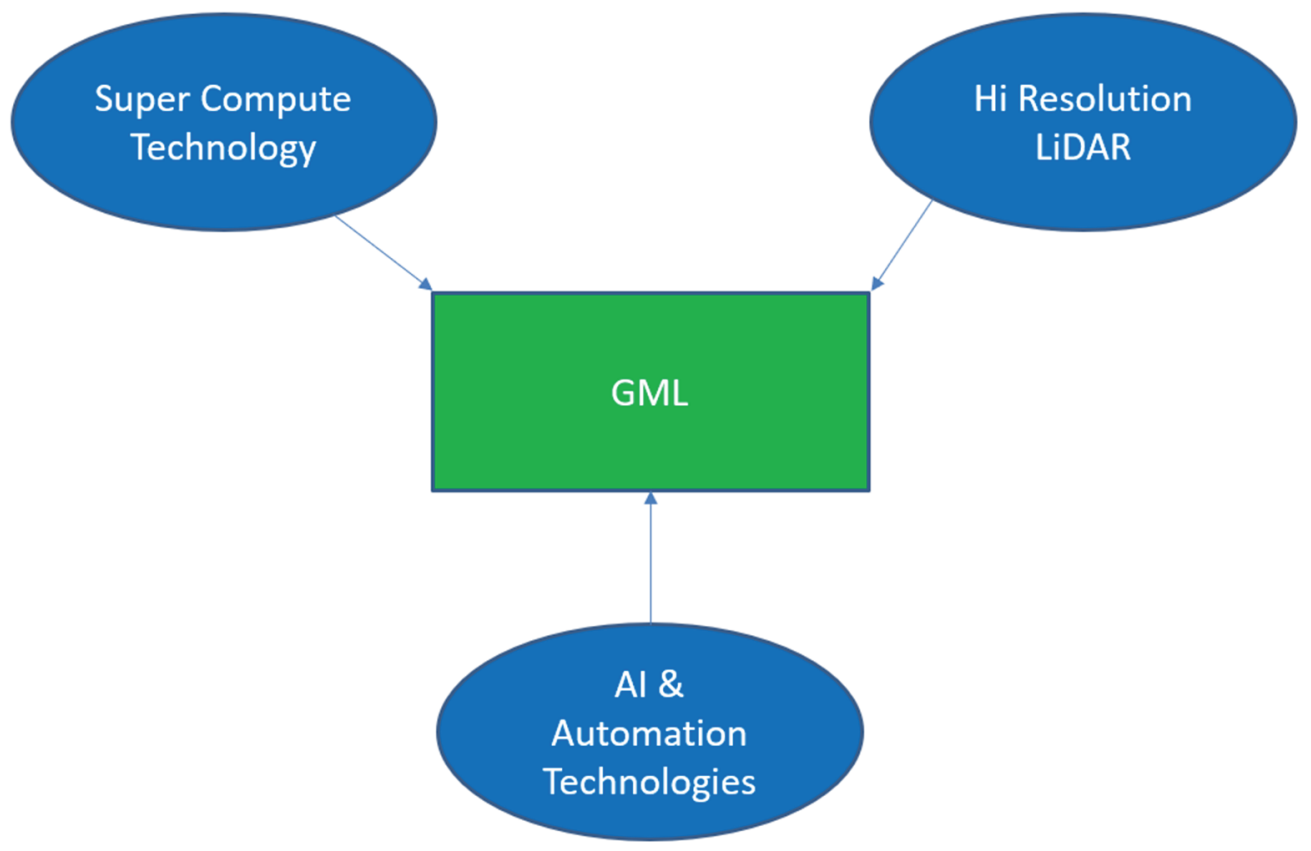

Figure 4 GML system architecture 
Current LiDAR technology from major vendors such as FARO, Leica, and Trimble, focuses on producing point clouds for mapping. The point cloud data is then post-processed to derive the desired results, such as shotcrete thickness or deformation information. The key differentiation between LiDAR and in situ LiDAR technology is the full automation of data acquisition, data transfer, data registration, and data processing, to produce live results to the construction crew.

The comparison between using a conventional LiDAR versus an Al assisted LiDAR technology is depicted in Figure 5 (Chen et al. 2020). This workflow comparison data was observed in both mining development and tunnel excavation operations. Being able to produce valuable construction data in situ, while the machine and crews are at the heading, significantly removes the delays and overheads associated with travelling and remobilisation of workforce.

\section{Typical Workflow Productivity Comparison}

\section{Typical Laser Scanner}

\section{Total: $4 \mathrm{hr} 45$ mins}
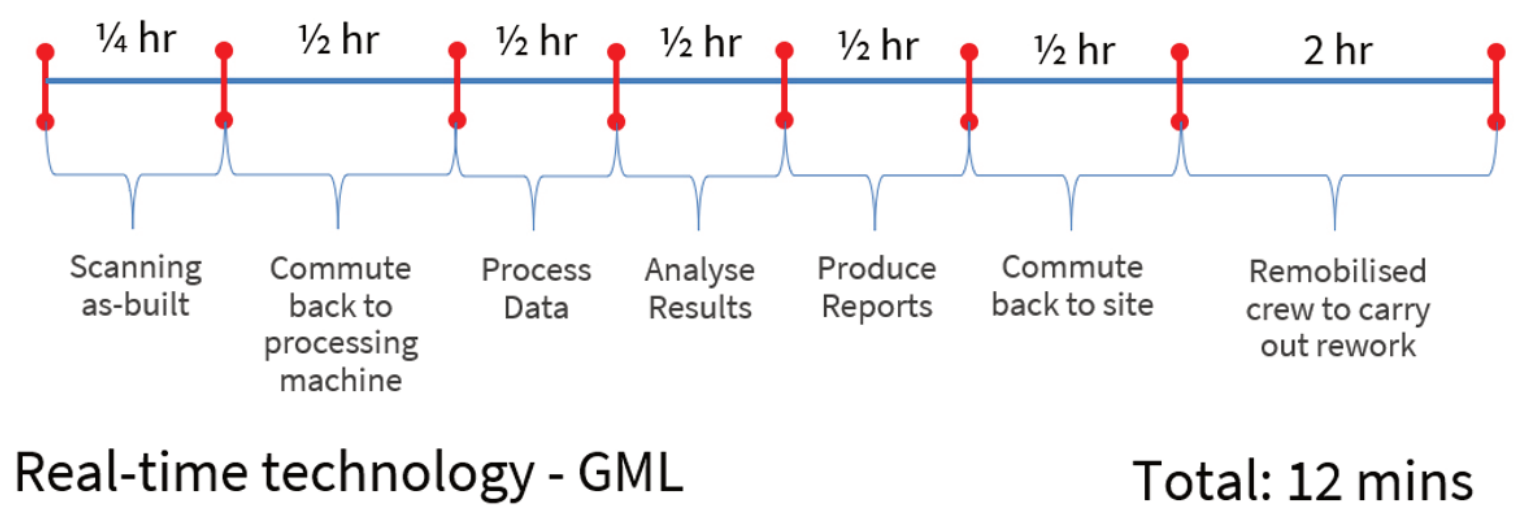

Total: 12 mins

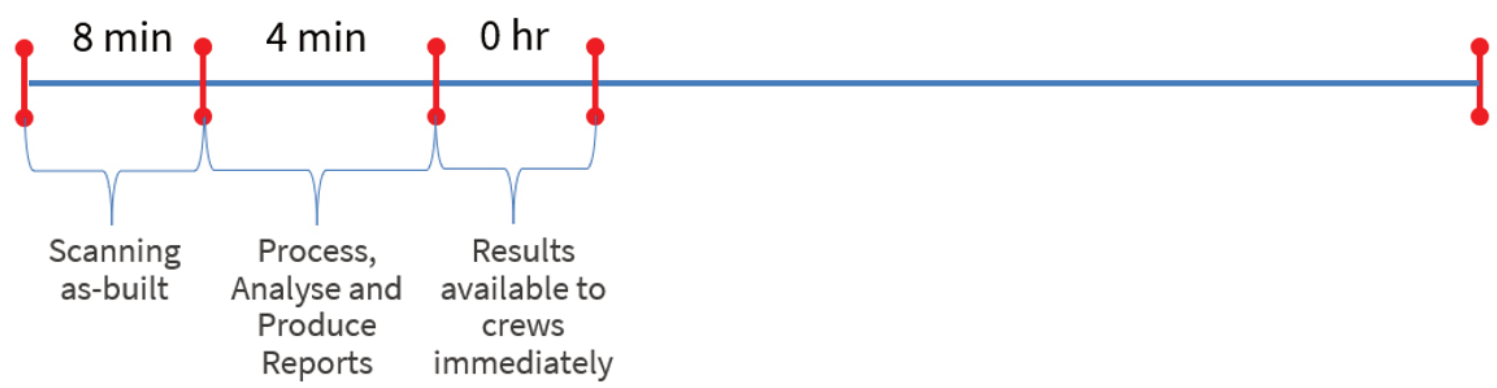

Figure 5 LiDAR versus Al assisted LiDAR workflow comparison

\section{Development cycle optimisation}

The GML technology has been used in the development cycle as shown in Figure 6. By providing live information to the construction crews, without manual processing, the technology was able to significantly improve the cycle time, quality, and material usage in the development cycle. This paper further discusses the results from the three key stages: drill-and-blast perimeter control, shotcrete verification, and measurement of the effectiveness of ground support. 


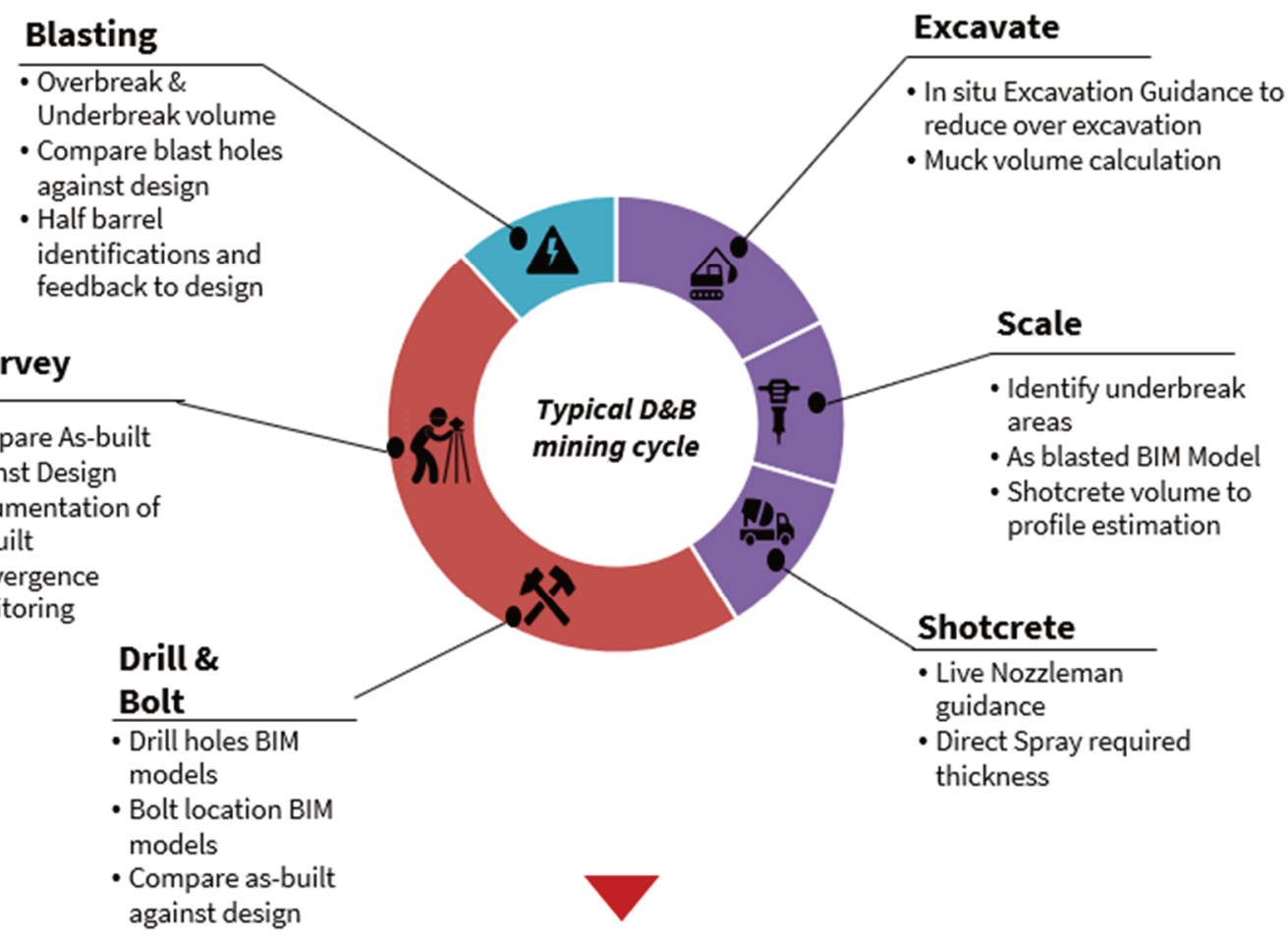

Figure 6 GML utilisation in mining development cycle

\section{Drill-and-blast perimeter control optimisation}

The ability to achieve perimeter control in a drill-and-blast operation has a significant impact to the advance rates and cost of development. This process involves the reconciliation of drill-and-blast data such as overbreak and underbreak volume, comparing pull length (achieved advance) against drill length and identification of half-barrels in perimeter holes to help identify and rectify the blasting issue. Ultimately, this needs to occur before the next round to minimise the overbreak and underbreak. Figure 7 shows the information provided by GML to the drill-and-blast engineer immediately after scanning.

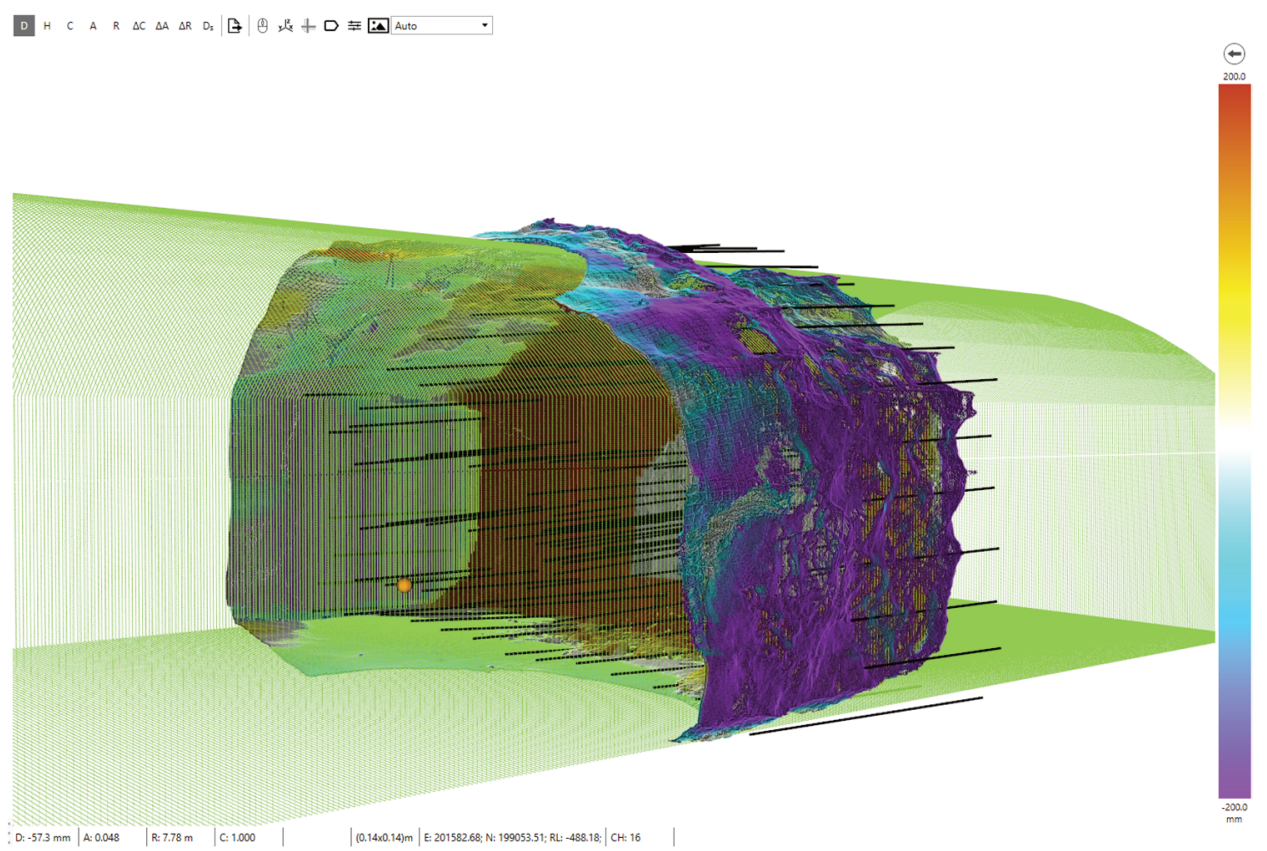

Figure 7 GML software showing perimeter control information 
Typically, the GML scan is captured after the blast once mucking has occurred, prior to any necessary scaling, to understand the as-blasted results. This then guides the crew to rectify any necessary underbreak prior to installation of ground support. By capturing the scan data, the system can automatically calculate the amount of underbreak $\left(\mathrm{m}^{3}\right)$ in the round, the amount of overbreak $\left(\mathrm{m}^{3}\right)$, the volume of the blast $\left(\mathrm{m}^{3}\right)$ and the achieved round length $(\mathrm{m})$ based on an average of points on the face. Utilising the achieved round length and the design round length, we can also calculate the pull efficiency of the blast (achieved round length/design round length).

Using this information, and by visualising the scan itself, we can start to understand the determining factors for the underbreak, overbreak or reduced pull efficiency. For example, if we are identifying overbreak on the left sidewall and underbreak on the right sidewall of the development, and this is not evident from checking the as-drilled versus as-designed round reports (i.e. they have been drilled close to the design), then there may be a calibration issue that needs checking on the drill rig. This information can be fed back to the drill rig operators to ensure that improvement is achieved on the next round by either checking the calibration of the drill rig, or if this is not possible, by manually adjusting the drill angles to mitigate this issue. The same can be applied if unfavourable jointing is featuring in the geology; we can adjust the drilling on the next round to mitigate these issues.

\subsection{Round-by-round underbreak reduction}

The reduction of underbreak is important to avoid any unnecessary clashes with equipment to be operated in the development or clashes in cases where any fixed shape equipment needs to be installed.

To understand if any underbreak or overbreak is occurring, the GML utilised the design profile of the excavation to check for any underbreak (surfaces inside the profile) or overbreak (surfaces outside the profile). Figure 8 shows the results from development of a dewatering cavern on a project in Australia, where red-yellow represents underbreak and blue-purple represents overbreak.

The project required tight tolerance for the installation of the final equipment, so it was essential that the excavation was scanned and checked for underbreak to avoid any clashes with the fixed dimension equipment. The heading was scanned after each blast and, in this example, underbreak was identified on the left sidewall at cut 6 . Once this was identified, the drill-and-blast engineer was able to adjust the drill design to account for this underbreak by slightly increasing the lookout angle to eliminate the underbreak. On cut 7 it was identified that the underbreak was reduced by making the adjustments, with some areas achieving the required profile, and by cut 8 the underbreak had been eliminated. Eliminating the underbreak ensured that the equipment would fit into the excavation and this meant that no rework was necessary.

s.

Comments:

Real-time Underbreak feedback to track blast outcome including the location and volume.

Used to feedback to driller or blast engineer to optimise blasting before the next round.

In Cut 48C8, they had rectified the underbreak.
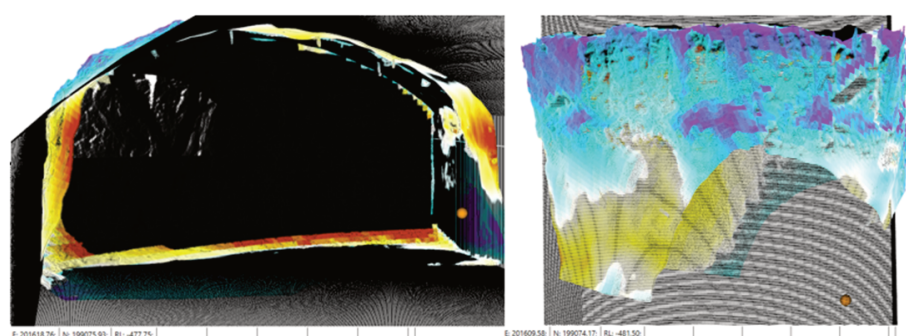

No More Underbreak

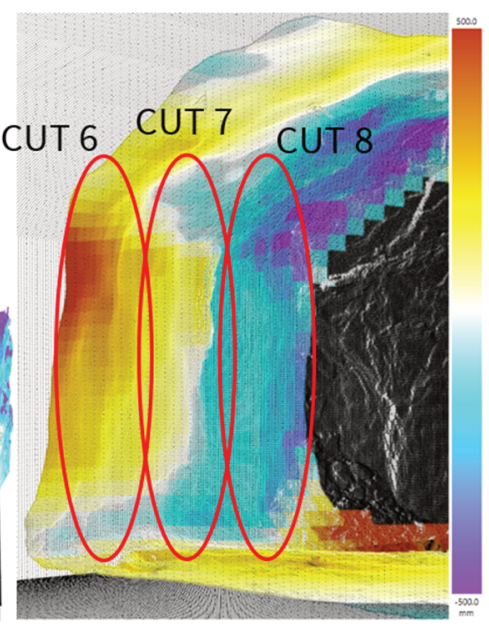

Figure 8 GML data showing round-by-round underbreak improvements 


\subsection{Round-by-round overbreak reduction}

Conversely, it is also important to reduce the amount of overbreak in the excavation since increasing the size of the excavation meant that more ground support was required, as well as hauling the additional rock; both of which contribute to increasing the cost of the works.

During the excavation works, overbreak was identified on the right sidewall in cut 10 (Figure 9). Since the scan data is captured with a very high level of detail, we were able to identify half-barrels on the right sidewall, which allowed us to understand that the overbreak was caused by the drilling. When this was identified in the scan results, the drill operator was instructed to reduce the lookout angle of the holes on the right side of the design to compensate for this overbreak. In cut 11 , there was a reduction in the overbreak, and by cut 12 , this was within the acceptable tolerance. In providing this feedback to the operator before the next round, we were able to rectify this issue swiftly.

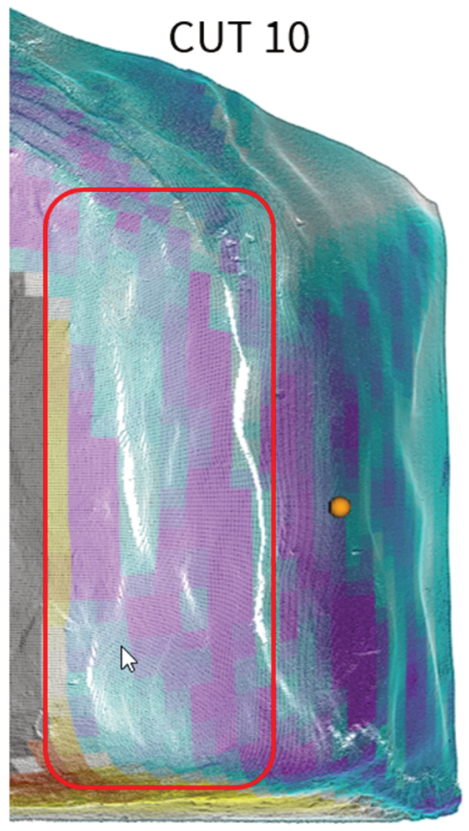

Overbreak: 350mm

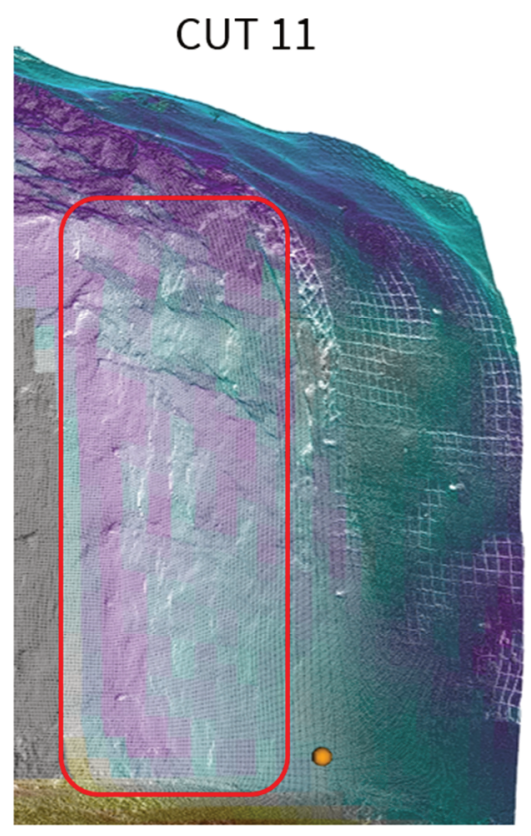

$300 \mathrm{~mm}$
CUT 12

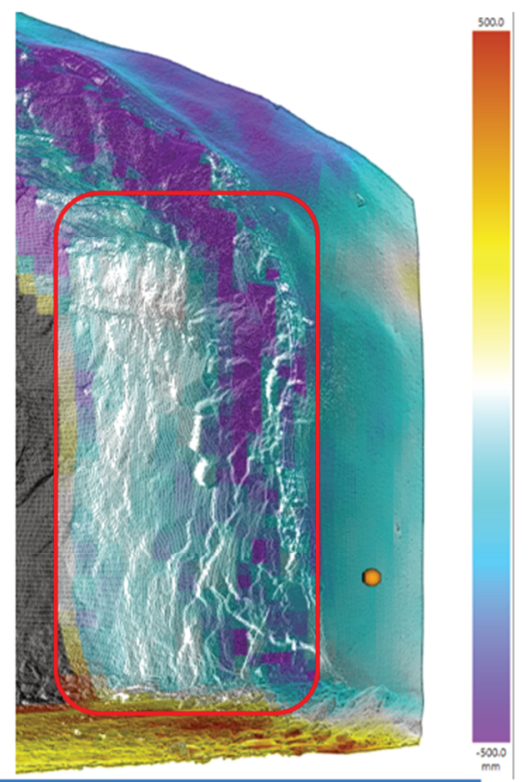

$200 \mathrm{~mm}$

\section{Figure 9 GML data showing round-by-round overbreak reduction}

\subsection{Control excavation against gantry crane profile}

Once the team had completed half of the excavation, an as-built scan of the area was completed to check the progress so far. Instead of utilising the excavation profile, which was used after each round to identify the underbreak and overbreak, the gantry crane operating envelop was used to understand if there were any potential clashes with the as-built excavation (areas coloured green represented no clash). Once the gantry crane profile was compared with the as-built scan, it identified one minor area of underbreak represented by the red-yellow colour in Figure 10. There was also an area where the excavation initially tapered out to the full width of the cavern, but the gantry crane would not extend into these areas, so this was not an area of concern. Once the minor area of underbreak was identified, the location of this was recorded from the scan data and it was established that the location of the gantry crane was adjustable, so this area of potential clashing did not require rectification. 


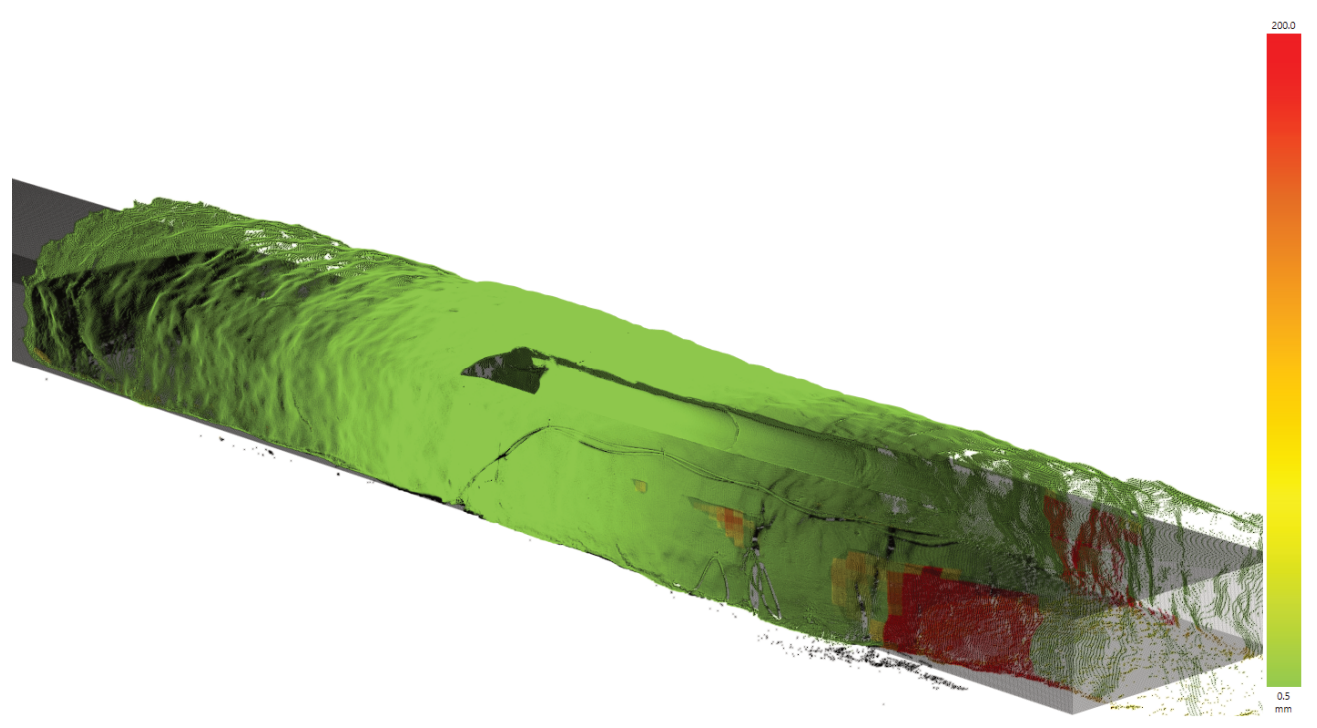

\section{Figure $10 \mathrm{GML}$ data show tight areas against gantry crane profile}

This accurate scan information allows the foresight of any potential issues. The benefits of being able to identify these clashes allows the excavation team to rectify any issues before the mobilisation of equipment and personnel to fit out the area. The cavern at this project was completed without any need for remedial work and is currently awaiting final fit out.

\section{Live shotcrete spray guidance}

The following case study is based on data from an Australian tunnelling project in 2018 (Chen et al. 2020). The project utilised GML to manage the sprayed shotcrete thickness for the primary lining ground support construction.

\subsection{Baseline spray quality}

At the start, GML was used to characterise the spray quality of the different nozzle operators. Figure 11 shows the typical spray quality before using GML to guide the nozzle operators. The shotcrete thickness in the images shows underspray areas in red, overspray areas in purple, and desired design thickness in green. As shown on the left of Figure 11, the sprayer was able to cover the bolts correctly but left large underspray gaps between the bolts. The other issue identified, was that often the nozzle operators would overspray the entire area just to ensure no underspray areas (as depicted on the right of Figure 11). Thus, using significantly more shotcrete than required.
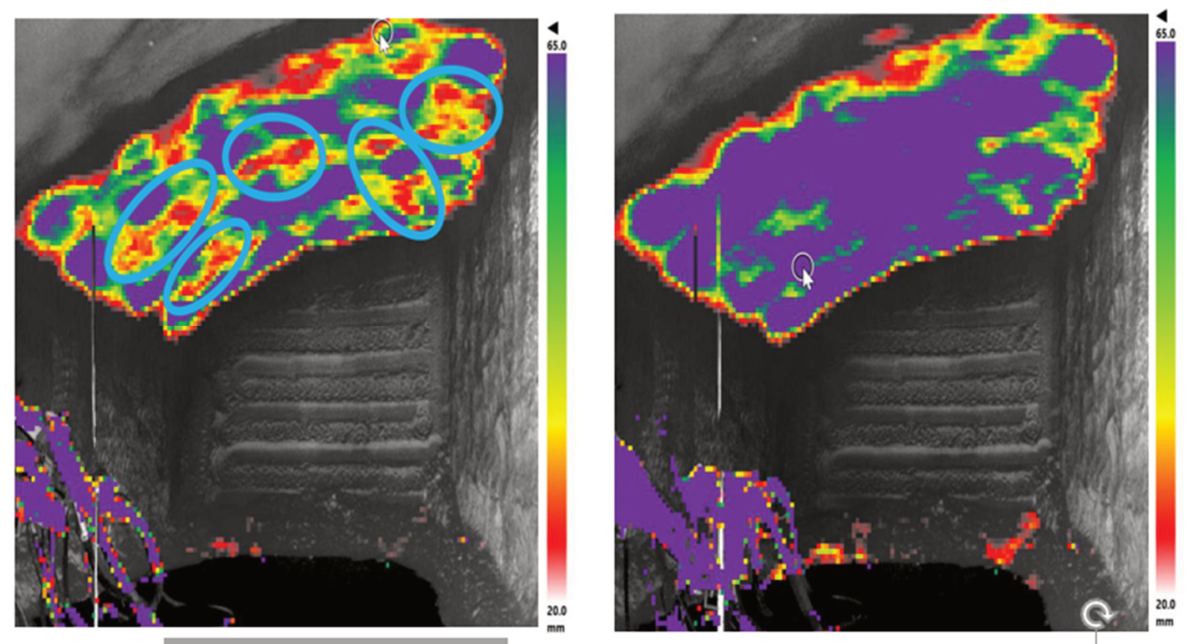

Figure 11 Detection of overspray and underspray shotcrete 


\subsection{Reducing thin areas}

Within the first four weeks of the project, after buy-in from site engineers, foremen and nozzle operators, the project was starting to see improvement of the spray quality. The sprayer was able to use GML guidance to cover up the thin spots as seen in Figure 12. However, there was still some small amount of underspray. Figure 12 shows the nozzle operator was able to detect thin areas and rectify them on the spot using GML.
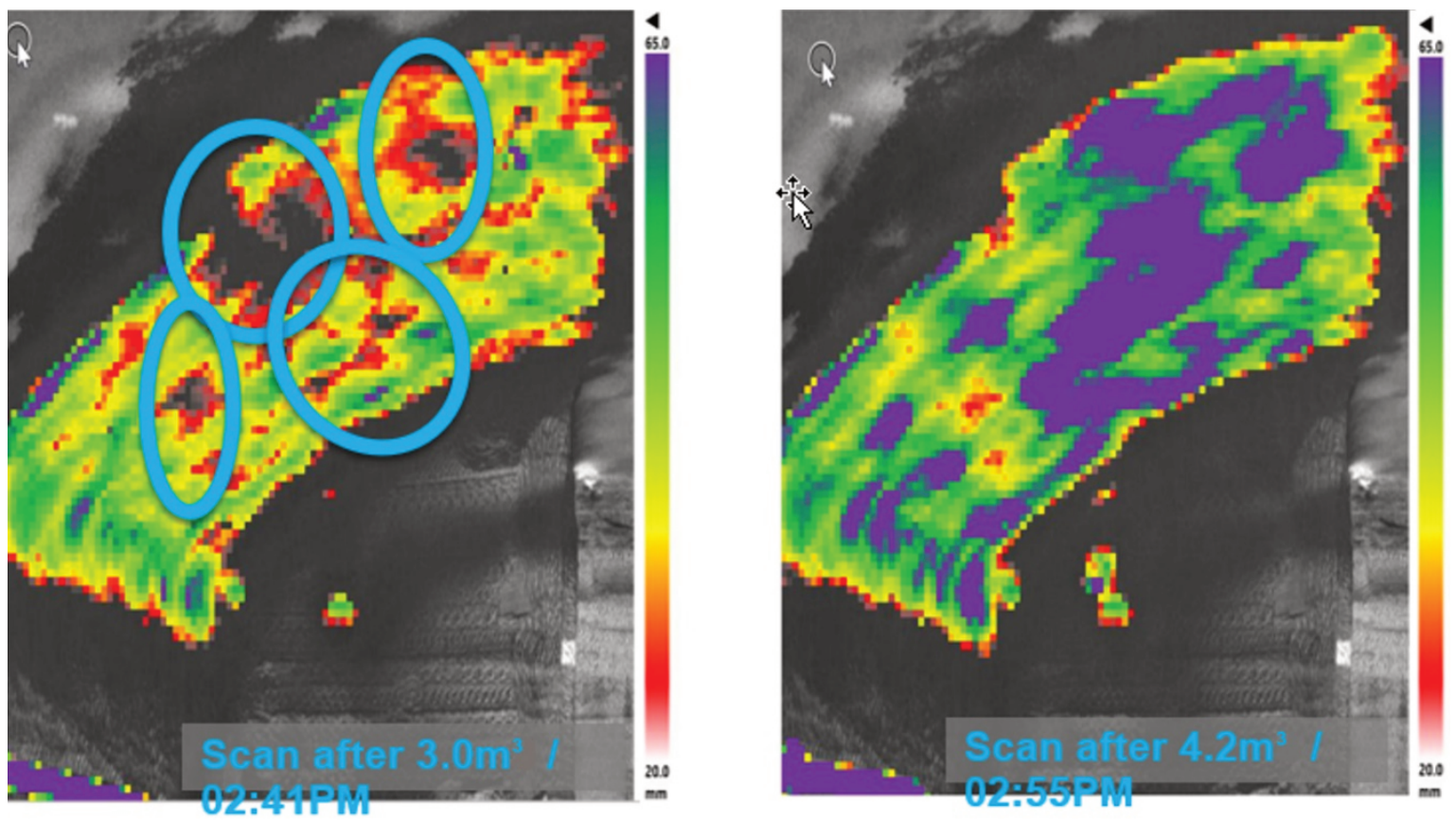

Figure 12 Nozzle operator guidance to reduce thin areas during shotcrete application

\subsection{Reduction in shotcrete usage}

Shortly after the first month, the majority of the nozzle operators were able to use the GML to guide their spraying to reduce the amount of overspray. Figure 13 shows the reduction of overspray areas. In this example, the nozzle operator was able to reduce shotcrete usage by $33 \%$ by using GML. More importantly, this was achieved within two weeks of working with the GML. Within the first month of utilising the GML, the shotcrete order amount was able to be reduced by $30 \%$ across the project.

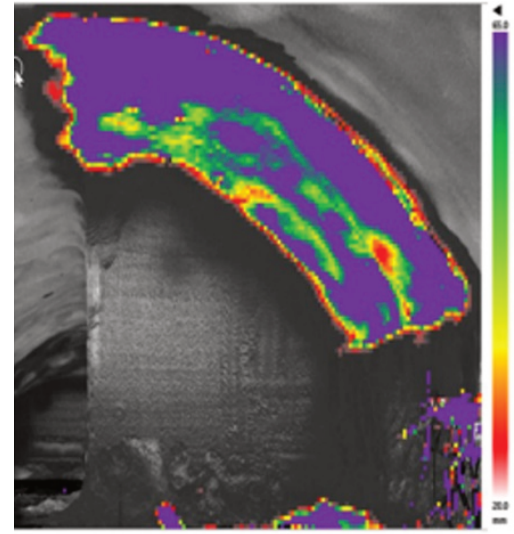

Scan details $(55 \mathrm{~mm}$

Date: $30 / 03 / 2018$

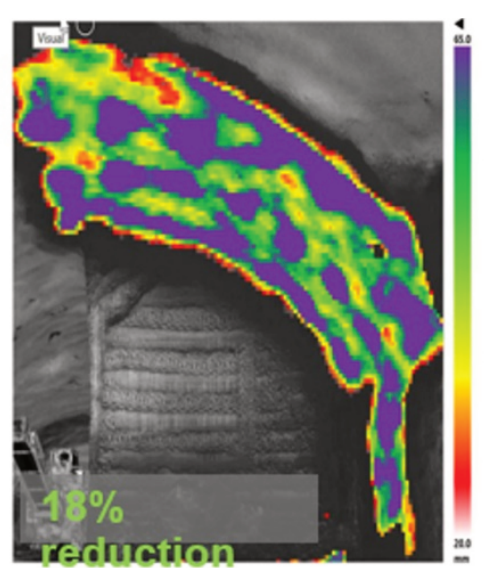

\section{Scan details $155 \mathrm{~mm}$} $\underline{\text { target) }}$

Date: $09 / 04 / 2018$

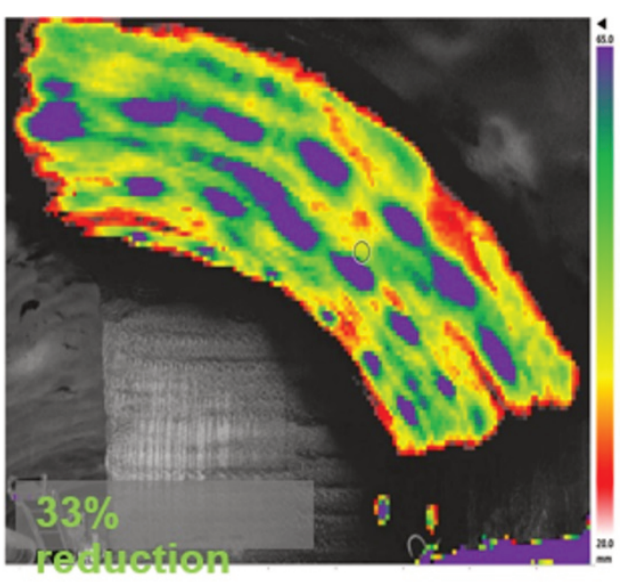

Scan details (55mm target)

Date: $11 / 04 / 2018$

Shotcrete sprayed: $\mathbf{4 . 0} \mathrm{m}^{3}$

Figure 13 Reduction of spray shotcrete by nozzle operators 


\section{$7 \quad$ Evaluate effectiveness of ground support}

This next case study is based on the paper published by the Agnico Eagle Geotechnical team in Canada titled Advanced geotechnical monitoring technology to assess ground support effectiveness (Gélinas et al. 2019). This paper was presented at the Ninth International Symposium on Ground Support in Mining and Underground Construction in 2019.

\subsection{Effectiveness of ground support during stope backfill and production blast}

GML was used to monitor the effectiveness of existing ground support in a drive before, during and after the backfilled operation with production blasting activities in neighbouring stopes. Table 1 shows the monitoring schedule against the related mining activities in surrounding areas.

Table 1 Summary of scanning and mining-related activities near the GML station GL11507

\begin{tabular}{ll}
\hline Date & Events \\
\hline 30 January 2019 & $360^{\circ} \mathrm{GML}$ scan \#1 \\
6 February 2019 & $360^{\circ} \mathrm{GML}$ scan \#2 \\
11 February 2019 & Start backfilling of adjacent Stope 115-128D \\
14 February 2019 & $360^{\circ} \mathrm{GML}$ scan \#3 \\
15 February 2019 & Blast \#1 of 9,000 tonnes in Stope 120-129C \\
17 February 2019 & End backfilling of adjacent Stope 115-128D \\
20 February 2019 & $360^{\circ}$ GML scan \#4 (am) and blast 18,000 tonnes (pm) in 120-129C \\
7 February 2019 & Final blast of 23,000 tonnes in 120-129C \\
7 March 2019 & $360^{\circ}$ GML scan \#5 \\
15 March 2019 & $360^{\circ}$ GML scan \#6 \\
\hline
\end{tabular}

The GML station was set up within the overcut in front of a secondary stope at a depth of 1,150 m. Figure 14a shows a plan of the scan location in front of the future Stope 120-129C and the backfilled primary stopes on either side. During the monitoring period, activities included the backfilling of Stope 115-128D and blasting of Stope 120-129C. Figure 14b Section AA shows the complete primary ground support and cablebolting pattern in the stope overcut. The double bulge cable bolts in the stope backs were tensioned and plated. The deformation response for each type of ground support element was measured and analysed over a series of periodic scans from the same location, identified as GL11507. 


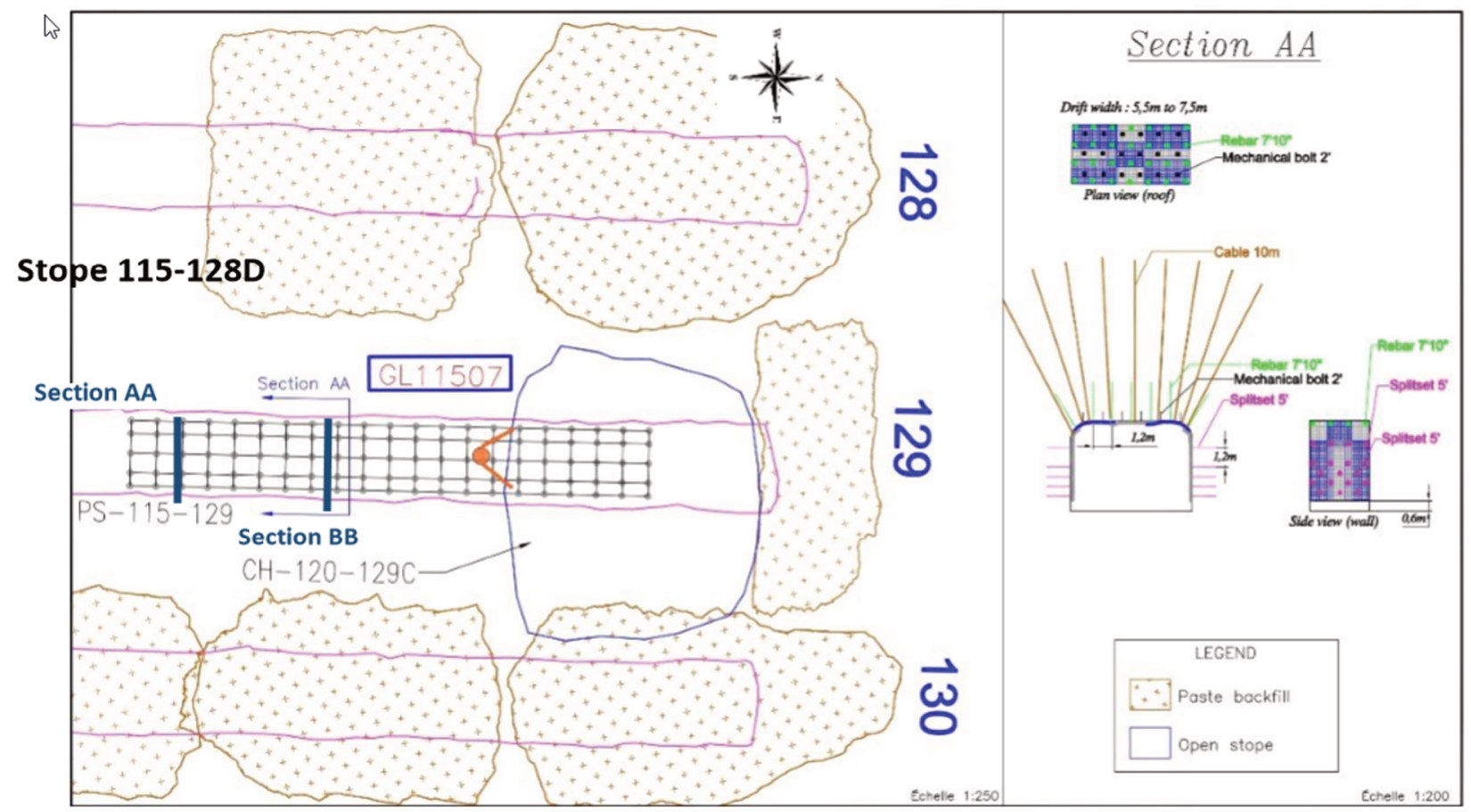

(a)

(b)

Figure 14 (a) Position of the GML station GL11507 on plan with (b) Cross-section showing ground support and cable-bolting pattern

After commencing the backfilling of Stope 115-128D, it was noticed that the west wall and bolts in the 115-129 drawpoint indicated a higher rate of deformation than the east wall. This effect was also directly linked with the observation of water draining through the west wall. As backfilling continued in Stope 115-128D, water was observed draining through the pillar, with Stope 115-128D into the drive where the GML station was located. The measured deformation between 30 January and 20 February, before the first blast of Stope 120-129C, is depicted in Figure 15b. As there was no blast-induced stress change during this period, the observed positive deformation of approximately $10 \mathrm{~mm}$ is related to the transient water pressure within the drawpoint pillar. Hot colours in the images represent positive deformations with the wall moving towards the scanner. Cold colours indicate negative deformations and are related to loss of material from the wall surface.

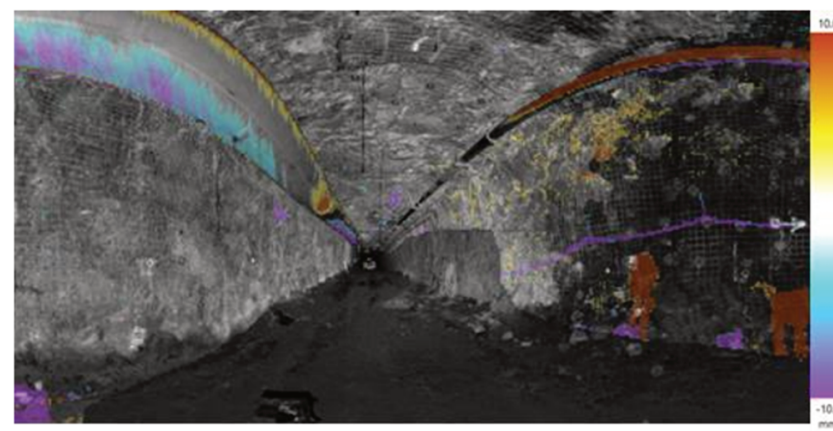

(a)

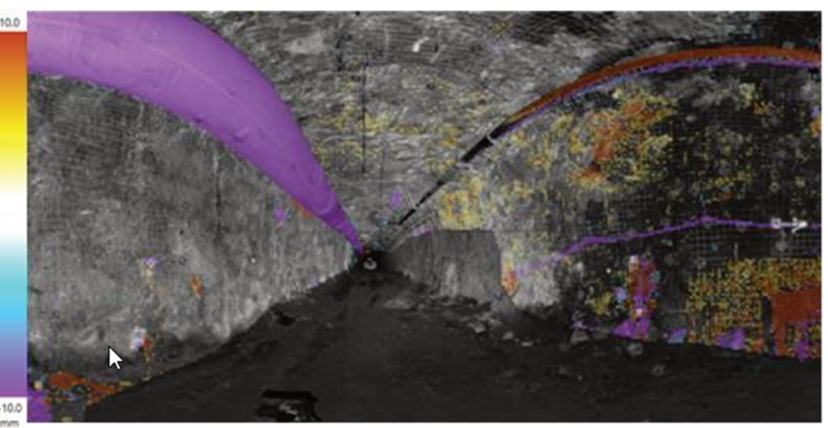

(b)

Figure 15 Detection of deformation between (a) 30 January and 14 February 2019; (b) 30 January and 20 February 2019

Figure 16 shows the location of the selected point measurements that were on the walls and roof to track the excavation deformation history over the entire duration of the scans conducted from 30 January to 15 March 2019. As repeated scans were conducted at this station, measurement points had to be carefully 
selected to avoid obstruction by cables, pipes, machinery, and fences and to avoid multiple screen overlap. Two Split Sets were chosen in each wall and three bolts on the roof.

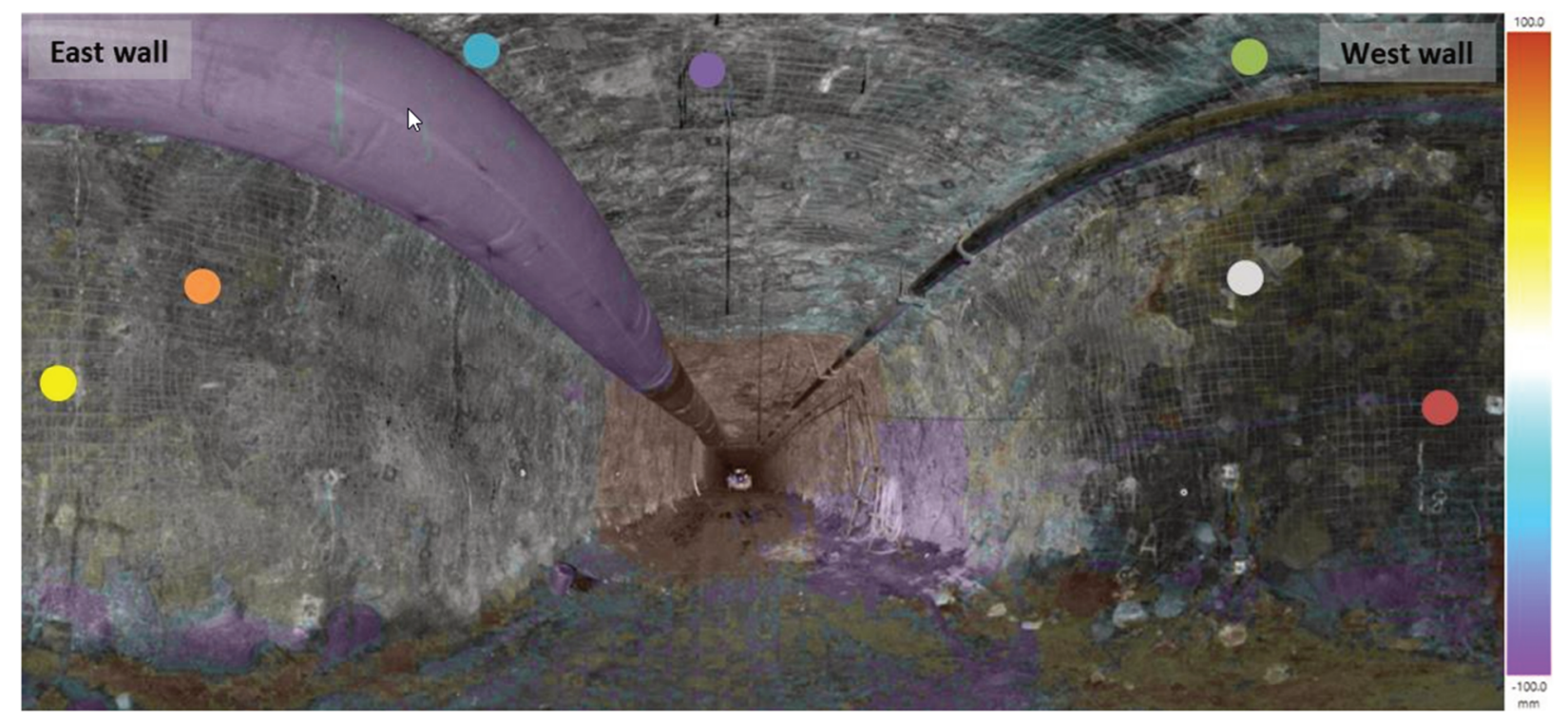

\section{Figure 16 Selected monitoring points for Station GL11507}

Figure 17 shows a graph of the deformation history of the bolts and wall surfaces at the locations identified in Figure 16. The scans concur with visual field observations of the west wall deforming more than the east wall. Figure 17 reveals that the west wall deformed significantly more compared to the east wall on the selected section. Moreover, it also indicates a step change in deformation with the third and last blast in Stope 120-129C. The last scan, more than two weeks later, shows no further deformation post-blast.

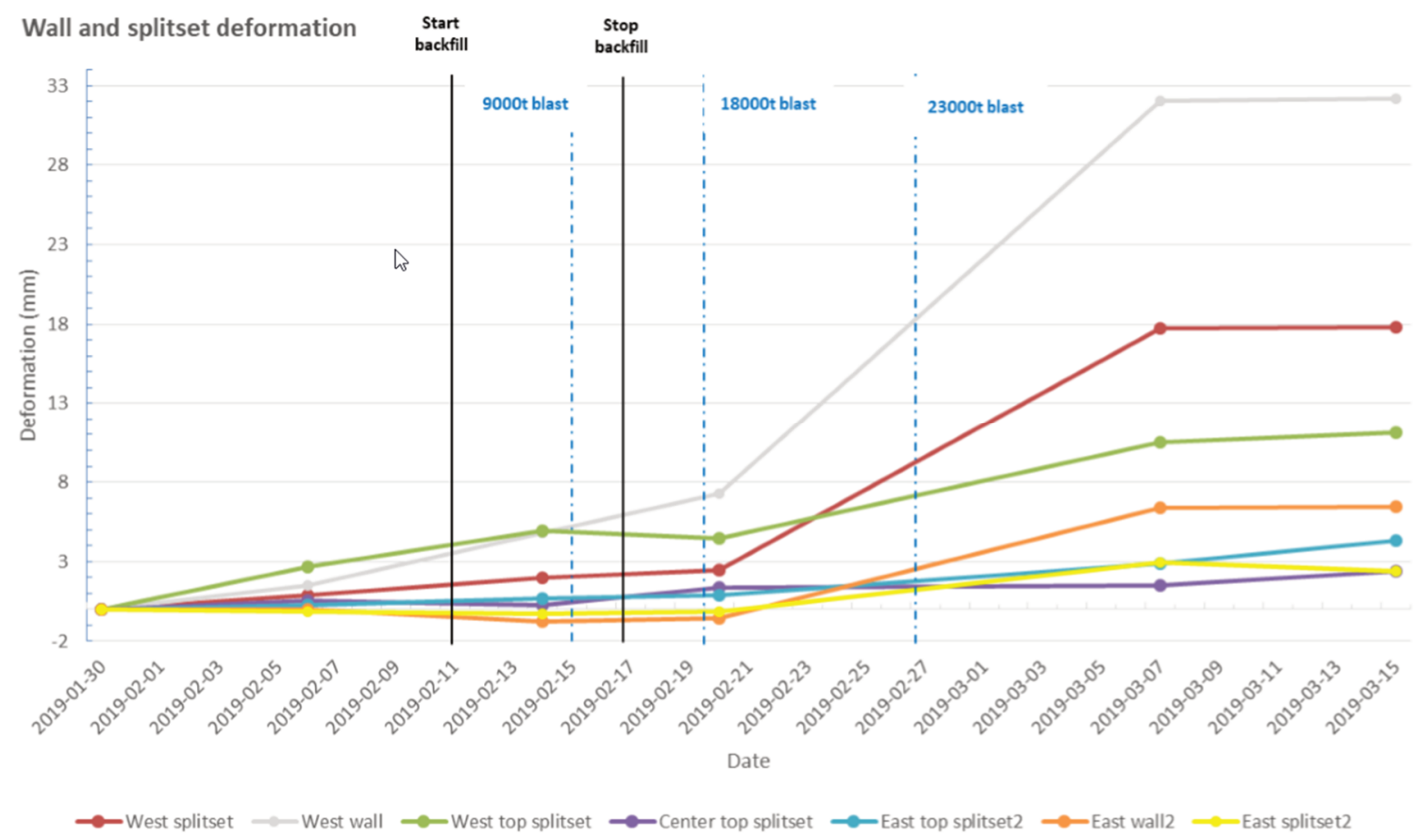

Figure 17 Deformation graphs of selected points in Station GL11507 
The automated processing capability of the GML was able to provide the aforementioned information immediately to the geotechnical team. This allowed for in-depth analysis on the effectiveness of different ground support used in their mining operations. Such analysis is very difficult to carry out using a conventional LiDAR technology as the process will be significantly drawn out.

The team at Agnico Eagle, Canada was able to isolate and cross-correlate the deformation movements to the mining activities and characterise the effectiveness of their ground support with the aid of real-time in situ measurement technology. The value of automated in situ technology in significantly reducing the overheads of such tasks is illuminated in this case study., thus making it now possible to provision ground support strategy for an active mining environment.

\section{Conclusion}

In this paper we discussed the fast progression of Al, LiDAR and computing technology that enabled the development of near real-time, Al assisted measurement solutions. This paper also provided examples of how such technology overcomes some of the challenges faced in mining development cycles. More importantly, we also explored the benefits of adopting such technology into the mining development cycle. However, to reap the benefits of such technology requires bold and innovative thinking at the site level, as decisions need to be made to adjust the excavation cycle to work around the limitations of these emerging technologies. Last but not least, such technology has the potential to contribute to more sustainable mining practices.

\section{Acknowledgement}

Firstly, the authors thank the Orica technical services team along with the analysis and improvement (A\&I) team from BHP for the opportunity to implement the GML technology into their projects. We thank the good work done by the geotechnical team, led by Veronique Falmagne, from Agnico Eagle, Canada for their hard work in challenging the state-of-the-art and achieving unprecedented results as seen in the publication referenced in this paper. We also thank the construction management team from the WestConnex project for their progressive and innovative leadership that resulted in the successful implementation of real-time technology into their excavation cycle.

\section{References}

Bergmann, NW 2005, 'FPGA-Based reconfigurable system-on-chip', in A Osseiran, S Lachowica, R Reis, HJ Pleiderer \& S-M Kang (eds), Proceedings of the Very Large Scale Integration System-on-Chip (VLSI-SoC2005), International Federation of Information, Perth, pp. 479-482.

Chen, B, Mares, D, Carter, N, Ayres, P \& Voysey, G 2020, 'Leveraging super-computing and high-density LiDAR technologies for realtime verification and rectification of tunnel construction against design', Proceedings of the ITA-AITES World Tunnel Congress (WTC 2020) and 46th General Assembly, paper ID 238.

Gélinas, LP, Falmagne, V, Bedard, B \& Matte, O 2019, 'Advanced geotechnical monitoring technology to assess ground support effectiveness', in J Hadjigeorgiou \& M Hudyma (eds), Proceedings of the Ninth International Symposium on Ground Support in Mining and Underground Construction, Australian Centre for Geomechanics, Perth, pp. 59-74, https://doi.org/10.36487/ACG_rep/1925_02_Gelinas.

Xilinx 2019, Zynq MP core dual, retrieved 18 September 2019 from https://www.xilinx.com/content/dam/xilinx/imgs/blockdiagrams/zynq-mp-core-dual.png 
